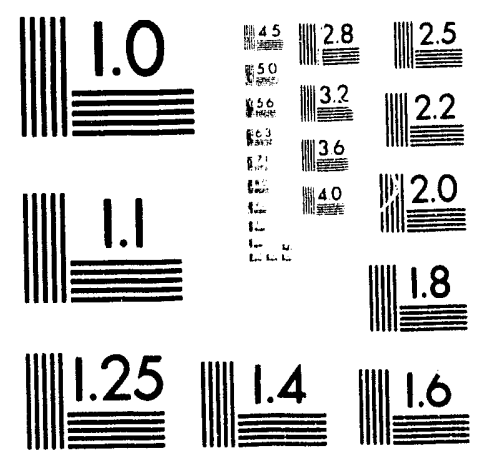



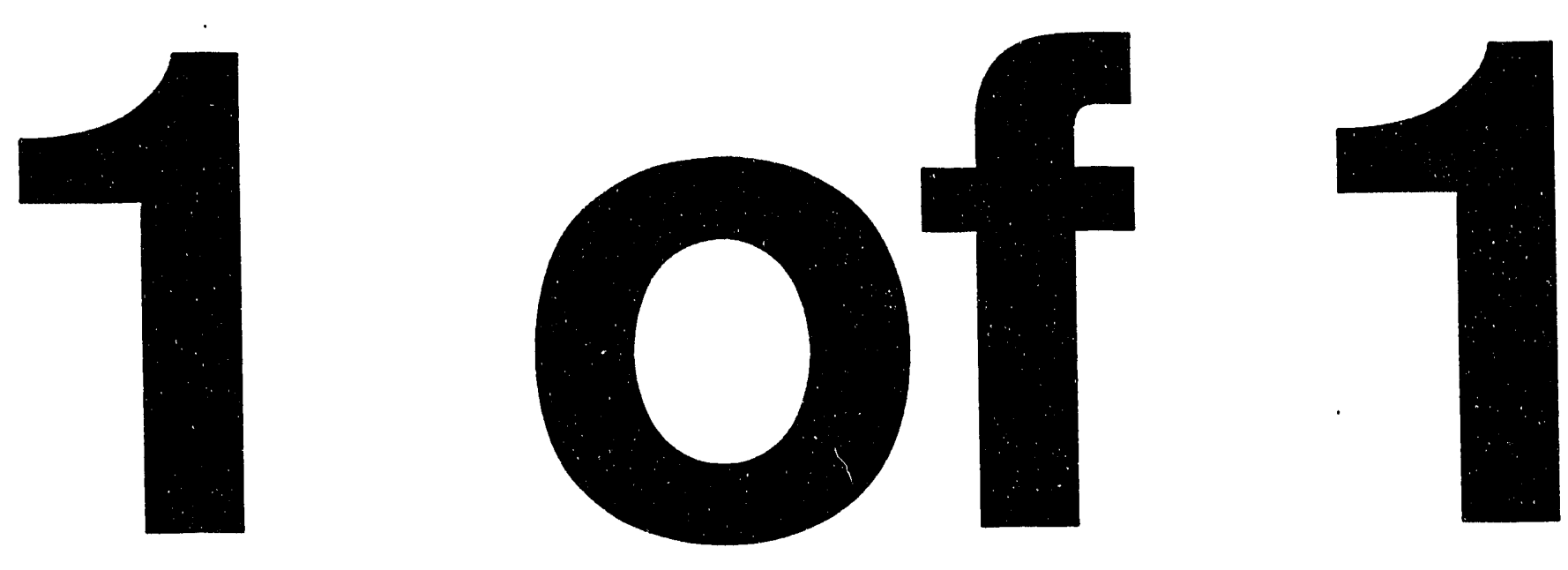


\section{PEP-II Prototype Klystron} \\ W. R. Fowkes, G. Caryotakis, T. G. Lee, C. Pearson, and E. L. Wright \\ Stanford Linear Accelerator Center \\ Stanford University, Stanford CA 94305
}

(A)

\section{Abstract}

A 540-kW continuous-wave (cw) klystron operating at $476 \mathrm{MHz}$ was developed for use as a power source for testing PEP-II $\mathrm{rf}$ accelerating cavities and $\mathrm{ff}$ windows. It also serves as a prototype for a $1.2 \mathrm{MW} \mathrm{cw}$ klystron presently being developed as a potential rf source for asymmetric colliding ring use. The design incorporates the concepts and many of the parts used in the original $353 \mathrm{MHz}$. PEP klystron developed sixteen years ago. The superior computer simulation codes available today result in improved performance with the cavity frequencies, drift lengths, and output circuit optimized for the higher frequency. The design and operating results of this tube are described with particular emphasis on the factors which affect efficiency and stability.

\section{INTRODUCTION}

The initial goal was to develop a $500-\mathrm{kW}$ cw klystron to operate at $476 \mathrm{MHz}$ for use as a power source for testing of cavities destined for the PEP-II Asymmetric Storage Ring. This tube is also considered as a prototype for a 1.2-MW klystron currently being developed as a potential ris source for PEP-II. It became apparent that the 500-kW cw PEP klystron operating at 353-MHz developed at SLAC sixteen years ago, might be used as a basis for scaling. Some quick calculations showed that the same gun, beam tunnel diameter, and collector could be used in a klystron operating at $476 \mathrm{MHz}$ and at the same power level of $500 \mathrm{~kW}$. The cavit; designs, drift tube lengths, and output circuit would have to be changed to operate at the new frequency. Many of the design concepts and some of the existing parts from the original PEP klystron could also be used on the $476-\mathrm{MHz}$ tube. It was determined that the development effort could be completed in approximately one year because of this similarity between the two klystrons. Approximately 175 new part and assembly drawings were required.

\section{COMPUTER CODE PREDICTIONS}

Both the one-dimensional JPNDISK and twodimensional CONDOR were used to compare the original $353-\mathrm{MHz}$ PEP design with its measured results. While the two codes gave different results and the absolute values in efficiency cannot be relied upon completely, the relative values are meaningful. Both codes predicted an optimized 476- $\mathrm{MHz}$ design efficiency about 8 percent higher than the $353-\mathrm{MHz}$ tube. It was also apparent that the efficiency of the 353-MHz PEP tube could have been higher using the now

\footnotetext{
- Work supported by Department of Energy contract
} DE-AC03-76SF00515.

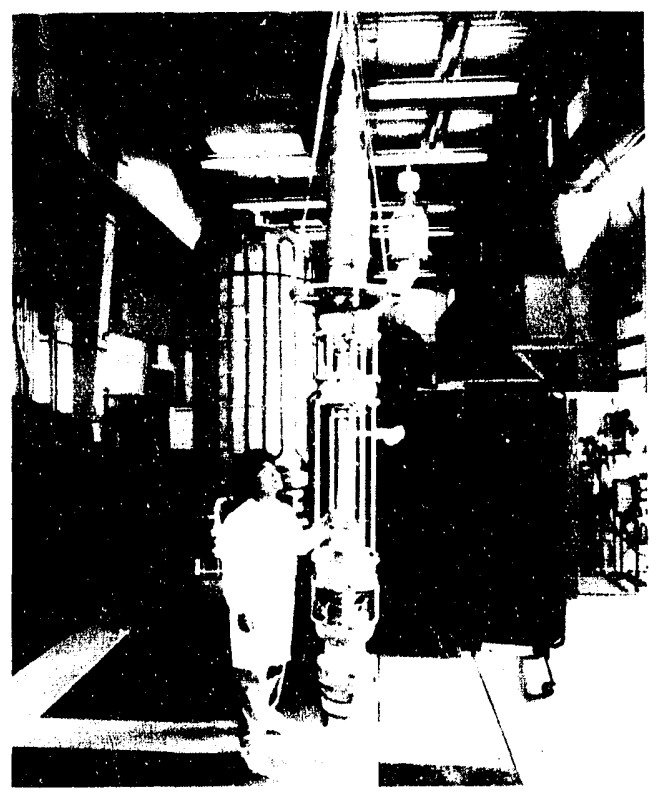

improved simulation codes, but this would have been at the expense of additional tube length.

\section{DESIGN}

The design parameters for the klystron are given below.

\section{DESIGN PARAMETERS}

\begin{tabular}{|c|c|}
\hline $\begin{array}{l}\text { Operating Frequency }(\mathrm{MHz}) \\
\text { Output Power }(\mathrm{kW} \mathrm{cW}) \\
\text { Beam Voltage (kV) } \\
\text { Buam Current (Amperes) }\end{array}$ & $\begin{array}{l}476 \\
540 \\
65 \\
12.4\end{array}$ \\
\hline Beam $\mu$ perveance $\left(\mu \mathrm{mp} / \mathrm{volt}^{3 / 2}\right)$ & 0.75 \\
\hline Efficiency & 0.67 \\
\hline Saturation Gain (dB min.) & 42 \\
\hline RF Drive Power (wauts) & $\leq 30$ \\
\hline Number of Cavities (Incl. 2nd Harm.) & 5 \\
\hline Normalized Drift Tube Radius, ya & 0.67 \\
\hline Normalized Beam Radius, $\gamma b$ & 0.43 \\
\hline Reduced Plasma Wavelength, $\lambda_{q}$ (meters) & 4.05 \\
\hline Output Waveguide & WR 2100 \\
\hline Focusing Magnetic Field (gauss) & $190(2.4 \times \mathrm{BBr})$ \\
\hline RF Interaction Length (meters) & 1.67 \\
\hline
\end{tabular}

The cathode is the dispenser type and the gun optics are identical to that of the PEP I klystron which had an oxide cathode operating at $353.2 \mathrm{MHz}$. The average loading is $98 \mathrm{~mA} / \mathrm{cm}^{2}$. The beam-tunnel diameter on both tubes is $7 \mathrm{~cm}$. The cavity geometries were changed to accommodate the 35 percent higher operating frequency, but most could be 
machined from the same stainless steel spinnings used on PEP I. The cavity diameters were unchanged from PEP I; the resonant frequencies were determined by cavity length and gap spacing. Cavity three, operating at the second harmonic, was an exception and had to be coinpletely redesigned. All five cavities are tunable, and cavities one through four have diagnostic loops. The drift tube lengths were all changed for optimum performance at $476 \mathrm{MAz}$ as determined by computer codes.

\section{INTERACTION SPACE PARAMETERS}

\begin{tabular}{lccccc}
\multicolumn{2}{c}{$\begin{array}{c}\text { Cavity Frequency } \\
\text { No. }\end{array}$} & $\begin{array}{c}\text { R/Q } \\
(\mathrm{MHz})\end{array}$ & $\begin{array}{c}\text { Thms) } \\
\text { (ohmsit Angle }\end{array}$ & $\begin{array}{c}\text { Qext } \\
\text { (radians) }\end{array}$ & $\begin{array}{c}\text { Drift } \\
\text { Lengths } \\
\left(360^{\circ} \times L \Omega_{0}\right)\end{array}$ \\
\hline 1 & 476.3 & 108 & 1000 & 0.95 & 35.4 \\
2 & 477.5 & 103 & $\infty$ & 1.14 & 11.4 \\
3 & 948.0 & 68 & $\infty$ & $0.80\left(@ 2 \times f_{0}\right)$ & 75.0 \\
4 & 483.8 & 106 & $\infty$ & 1.00 & 33.6 \\
5 & 476.4 & 102 & 70 & 1.00 &
\end{tabular}

The output coupling loop design that was used on PEP I did not provide enough coupling for the design external $Q$ of 70. The diameter of the output coax center conductor that forms the loop in the output cavity had to be tapered down from $3.34 \mathrm{~cm}$ to $1.91 \mathrm{~cm}$ in diameter. The coax-towaveguide transition ( $56 \Omega$ to reduced height WR 2100) that houses the cylindrical alumina ceramic window was not altered. The position of the abrupt step to full-height waveguide remained the same, but the inductive matching post was moved to provide a perfect match the waveguide to the $56-\mathrm{ohm}, 8.5-\mathrm{cm}$ diameter coax exiting the output cavity. The changes resulted in improved bandwith compared with the original PEP I output window assembly.

The final external Q achieved on the cold test model of the output cavity after five machining iterations was 70 , the design value. The measured external $Q$, however, on the brazed version destined for the tube turned out to be 57 . Unfortunately, no quick way of adjusting the coupling exists. It was decided to assemble the tube and optimize the external $Q$ artificially in the waveguide output as described later.

\section{OPERATING RESULTS}

The klystron began testing in spring 1992. The design power output of $500 \mathrm{~kW}$ was achieved at $66 \mathrm{kV}$ instead of the design value of $65 \mathrm{kV}$. The efficiency was slightly lower than expected due in part to a lower than optimum external $Q$ for the output cavity as described above. The initial measured efficiency was about 60 percent but was increased to 61.6 percent by artificially raising the external $Q$ of the output cavity with an external matching element and some minor tuning of three of the cavities. No instabilities, such as multipactor, spurious frequencies, or sideband frequencies due to returning electrons were observed. The beam is well behaved, and the usual tradcoff between focusing for maximum power output and minimum body interception was not present. The first two cavities and the entire output circuit were coated with titanium nitride as a precaution against multipactor.

A saturation gain of $40 \mathrm{~dB}$ was achieved instead of the design value of $42 \mathrm{~dB}$, and the optimum focus magnetic field was 234 Gauss instead of the design value of 190 Gauss. Plots of efficiency and gain are plotted as a function of $\mathrm{rf}$ drive in Figure 1.

\section{CHANGING THE EXTERNAL Q OF THE OUTPUT CAVITY}

The effective external $Q$ was changed by placing a capacitive post in a section of waveguide with a longitudinal slot along its centerline on one broadwall so that the gap impedance could be changed by controlling the height and position of the post. The initial assumption was that the gap impedance should be increased by approximately the ratio

$$
\sigma=\frac{Q_{\text {ext-desired }}}{Q_{\text {ext-actual }}}=\frac{70}{57}=1.23,
$$

and the magnitude of the nnrtialized capacitive susceptance to accomplish this is given by

$$
\left|\frac{B}{Y_{0}}\right|=\frac{\sigma-1}{\sqrt{\sigma}}=0.206 \text {. }
$$

The location of the capacitive post with respect to the outputcavity detuned short is given by

$$
\ell=\frac{\lambda_{8}}{4}+\frac{\lambda_{8}}{2 \pi} \tan ^{-1}\left[\frac{1}{2}\left[\sqrt{\left|\frac{B}{Y_{0}}\right|^{2}+4}-\left|\frac{B}{Y_{0}}\right|\right]\right]
$$

towards the load. This produces a normalized admittance at the detuned short position of

$$
\frac{Y}{Y_{0}}=0.814+j 0
$$

Capacitive post spacers were constructed to produce capacitive susceptances slightly larger and smaller than the calculated value, but the calculatid value was found to be optimun for improving efficiency. The effect on efficiency of the $z$ position in the slotted waveguide is shown in Figure 2.

\section{FUTURE PLANS}

A 1.2 MW klystron operating at the same frequency is jointly being developed by SLAC and Varian Associates. This new tube must have a combination of wide bandwidth and short group delay needed for powering high-current accelerator systems requiring fast if feedback stabilization. The bandwidth and group delay of the $500 \mathrm{~kW}$ klystron 
described in this paper are not adequate. The first tube will be built and testres at SLAC but the design will be a joint effor by both organizations. Testing of this tube is expected to s:art in the summer of 1994.

\section{ACKNOWLEDGMENT}

The authors would like to acknowledge the members of the klystron manufacturing and testing groups who put their energy, dedication and skill together to bring this project together within a year of its inception. Particular thanks go to Harry Greenhill and Charley Griffin who made many valuable contributions to the tube design and testing facility.

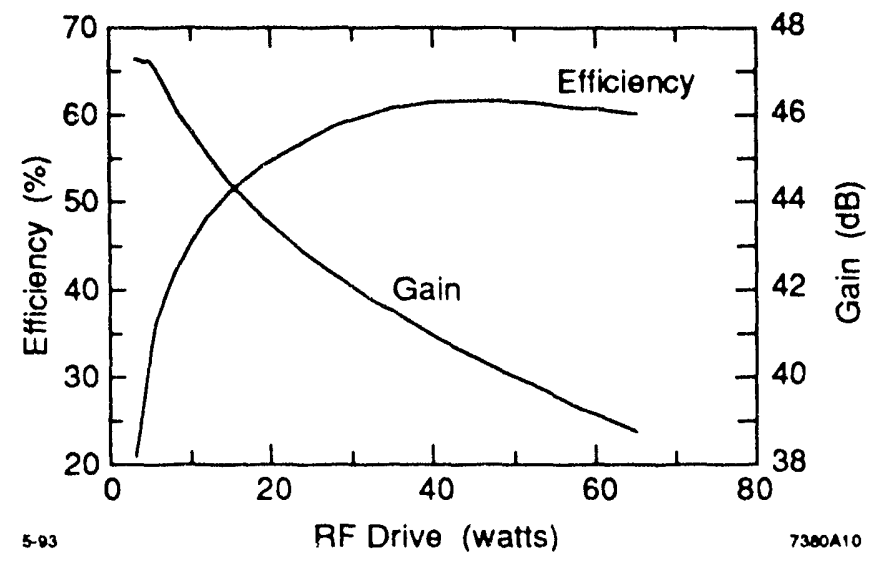

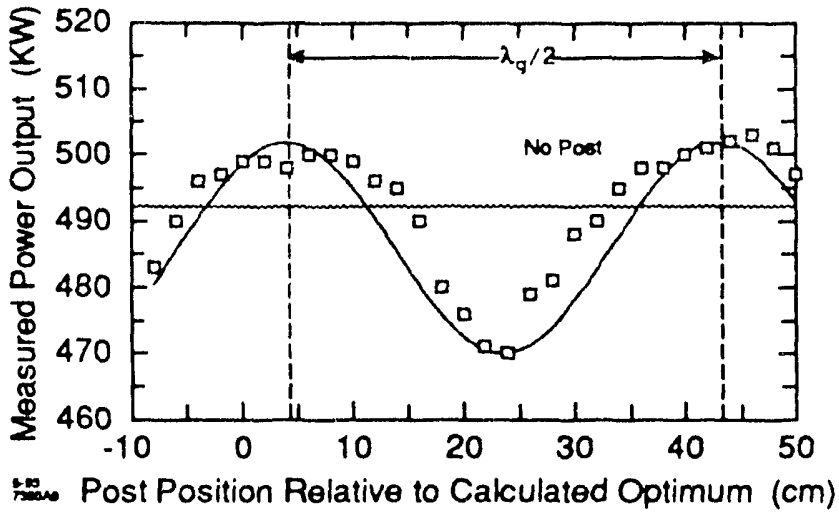

DISCLAIMER

This report was prepared as an account of work sponsored by an agency of the United States employees, makes any warranty, expres Government nor any agency thereof, nor any of their bility for the accuracy, completeness, or usefulness, or assumes any legal liability or responsiprocess disclosed, or represents ence herein to any specific commercials use would not infringe privately owned rights. Refermanufacturer, or otherwise does not necesart, process, or service by trade name, trademark, mendation, or favoring by the United States constitute or imply its endorsement, recomand opinions of authors expressed herein United States Government or any agency thereof. not necessarily state or reflect those of the 

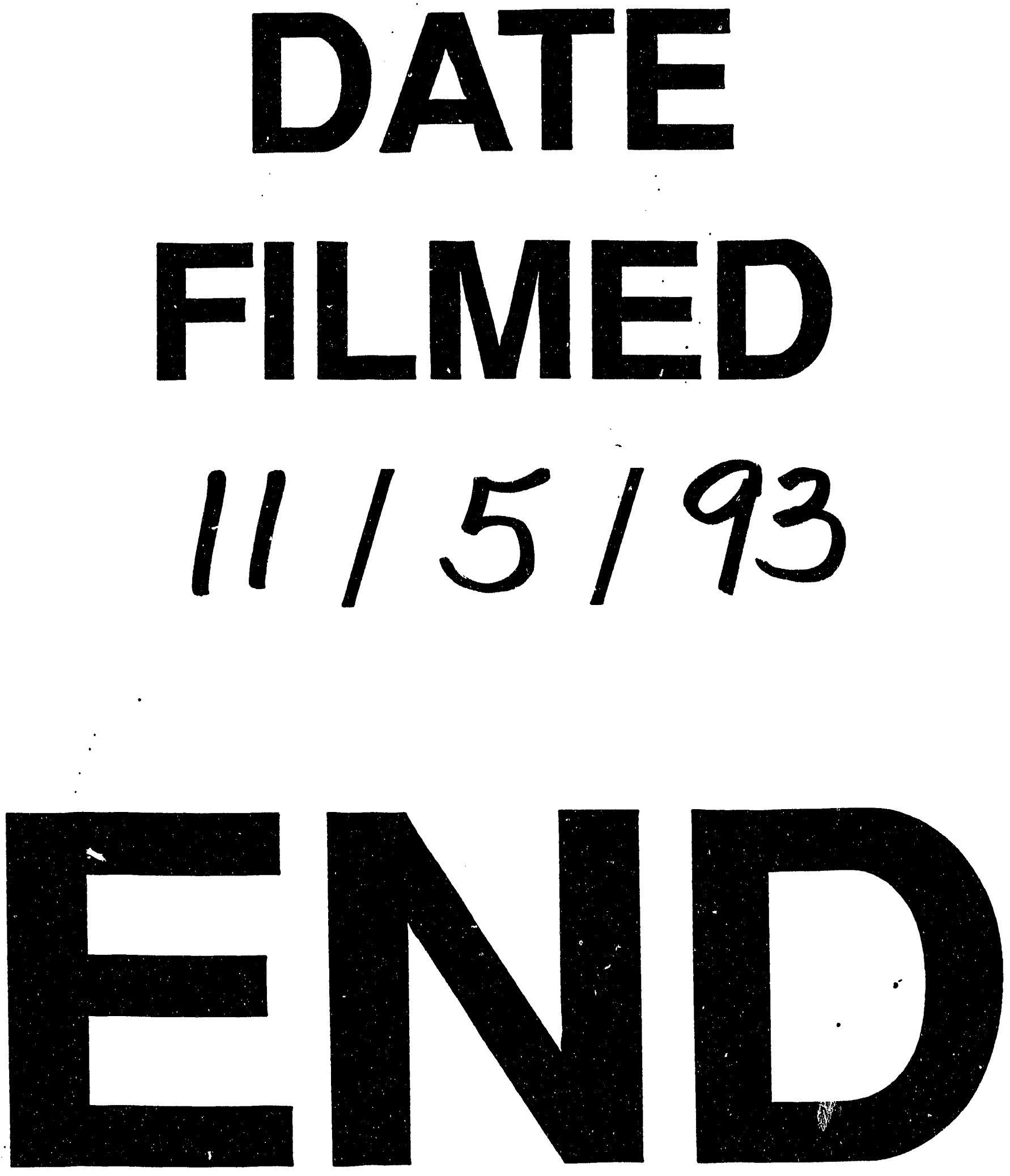
